archives-ouvertes

\title{
Mechanical properties of high density polyurethane foams: I. Effect of the density
}

\author{
Fabrice Saint-Michel, Laurent Chazeau, Jean-Yves Cavaillé, Emmanuelle
}

Chabert

\section{To cite this version:}

Fabrice Saint-Michel, Laurent Chazeau, Jean-Yves Cavaillé, Emmanuelle Chabert. Mechanical properties of high density polyurethane foams: I. Effect of the density. Composites Science and Technology, Elsevier, 2006, 66, pp.2700-2708. 10.1016/j.compscitech.2006.03.009 . hal-00111453

\section{HAL Id: hal-00111453 \\ https://hal.archives-ouvertes.fr/hal-00111453}

Submitted on 23 Jul 2019

HAL is a multi-disciplinary open access archive for the deposit and dissemination of scientific research documents, whether they are published or not. The documents may come from teaching and research institutions in France or abroad, or from public or private research centers.
L'archive ouverte pluridisciplinaire HAL, est destinée au dépôt et à la diffusion de documents scientifiques de niveau recherche, publiés ou non, émanant des établissements d'enseignement et de recherche français ou étrangers, des laboratoires publics ou privés. 


\title{
Mechanical properties of high density polyurethane foams: I. Effect of the density
}

\author{
Fabrice Saint-Michel ${ }^{\mathrm{a}}$, Laurent Chazeau ${ }^{\mathrm{a}, *}$, Jean-Yves Cavaillé ${ }^{\mathrm{a}}$, Emanuelle Chabert ${ }^{\mathrm{b}}$ \\ ${ }^{a}$ Groupe d'Etude de Métallurgie Physique et Physique des Matériaux, UMR CNRS 5510, Bât. Blaise Pascal, 69621 Villeurbanne Cedex, France \\ ${ }^{\mathrm{b}}$ Laboratoire de Mécanique des Solides, Ecole Polytechnique, UMR CNRS 7649, 91128 Palaiseau Cedex, France
}

\begin{abstract}
This article presents the mechanical behaviour of rigid polyurethane foams with relative density $\left(\rho_{f} / \rho_{s}\right)$ above 0,3 . The parameter taken into account is the density, which controls the foam architecture. The mechanical properties of the foams, characterised by large deformation compression tests and dynamic mechanical analyses, were compared to two theoretical models: (i) the Gibson and Ashby approach, widely used for foam description and (ii) the $2+1$ phase model from Christensen and Lo, generally used for the description of particulate composite materials. In the studied density range, it is shown that the second approach is more appropriate. Moreover, the stress-strain curve and in particular yield stress have been modelled using two different approaches by extension of this model to the nonlinear domain.
\end{abstract}

Keywords: Polyurethane foam; B. Mechanical properties; B. Modelling; C. Complex moduli

\section{Introduction}

Polymer foams are more and more used in industry. Made of a skeleton of more or less regular open or closed cells, they have a high energy absorption capacity, particularly useful for shock applications, acoustic and thermal insulating properties, in some cases, filtering applications, etc. For these reasons, they are widely used in aircraft industry, automobile, buildings, packaging... [1,2]. Combining good mechanical properties with a low density, rigid polymer foams can also be used as structural materials. Whatever their use, their optimisation needs the understanding of their microstructure-mechanical properties relationship. Indeed, the mechanical response of these materials depends on their architecture, and on the intrinsic properties of the polymer in the cell wall [1]. The architec-

\footnotetext{
${ }^{*}$ Corresponding author.

E-mail address: Laurent.chazeau@insa-lyon.fr (L. Chazeau).
}

ture is determined by the cell wall thickness, the size distribution and the shape of the cells.

The literature contains many trials to predict the behaviour of these materials. Theoretical studies on foam have mainly addressed the behaviour of low density foams. The structure of these foam are simulated by a compact assembly of walls and struts. All these models can be divided in two groups. On the one hand, there are complex modelling approaches based on finite element method $[3,4]$ which try to describe as finely as possible the foam microstructure. On the other hand, there are simpler and more numerous models which largely simplify this microstructure [1,5-9]. These models, such as that of Gibson and Ashby [1], are based on the assembly of geometric symmetric cells (rectangular prism, cubic...) and relate analytically elasticity and yield stress to the foam relative density.

In the case of very high density foams, made of spherical cells that are closed and isolated ones from the others, the materials can be considered as porous. Then their modelling can be done using existing theories for composite material description. Siegmann et al. [10], have correctly 
predicted elastic properties of polyurethane foams using the Kerner equations [11]. For this purpose, they have considered these materials as composites made of void inclusions in a matrix. Of course the assumption of closed isolated spherical cell is less and less valid when decreasing the density of such materials, while the structure simplifications and approximations made by the Gibson and Ashby model become more and more pertinent.

Therefore, it seems interesting to evaluate what is the most appropriate model to describe the mechanical properties of studied foams in a density range of $[0.3 ; 0.8]$, i.e. a density range, where both models might be applied. This is the question addressed by this article, which presents the microstructural characterisation and the mechanical behaviour of such materials. In a first part, the influence of the density, and of the intrinsic mechanical properties of the matrix is characterised, and the foam morphology is precisely determined by electron microscopy. The mechanical characterization associates large and small deformations tests. The experimental results are then compared in the linear domain to the theoretical approaches of Gibson and Ashby [1] and Christensen and Lo [12]. Moreover, the modelling is then extended to the description of the mechanical behaviour in the non-linear domain.

\section{Experimental}

\subsection{Materials}

The foams studied are formulated from a polymer matrix made of polyols, catalysts, and a surfactant. This matrix is mainly constituted of two polypropylenes triols (polyols) supplied by Shell Chemicals. The silicone surfactant is supplied by Air Products. Two catalyser are used. They are salts supplied by Air Products. The catalyser A is a dibutyltin dilaurate (DBTDL). The catalyser B is a $2,2^{\prime}$-[(dimethylstannylene)bis(thio)]diacetate. They accelerate the polymerisation reaction and regulate the reaction kinetic during the polyurethane foam expansion.

The foams are obtained by mixing the polymer matrix with a polyisocyanate, a diphenylmethanediisocyanate-4-4' (commonly called MDI). The reaction of the latter with polyols creates urethane bonds [13]. Water reacts with the polyisocyanate to produce carbon dioxide. This is the origin of the foam expansion. The water quantity added controls directly the foam density.

\subsection{Processing}

The components of the polymer matrix (polyol, surfactant, catalyseurs) are mixed at $600 \mathrm{rpm}$ during 2 min with a mixer (Rayneri) with rotating blades. This mix is then dried on a $4 \AA$ molecular sieve for $48 \mathrm{~h}$ to eliminate the residual water.

Distilled water and polyisocyanate are then added to the polymer matrix. The mix is then stirred at $1500 \mathrm{rpm}$ during $20 \mathrm{~s}$, then poured in a cylindrical plastic mould.
Foams are obtained by the free expansion in this mould during about $3 \mathrm{~min}$. Then the foam gels by polymerisation/crosslinking. The foam is then extracted from the mould after 30 min.

This foam block is then cut in three parts, two with dimensions $45 \times 20 \times 30 \mathrm{~mm}^{3}$ and one with dimension $80 \times 30 \times 40 \mathrm{~mm}^{3}$. The apparent density measurement is done by measuring the volume and the mass of this three blocks. The relative density $\left(D_{\mathrm{r}}\right)$ is defined by the ratio of the foam density $\rho_{\mathrm{f}}$ by the solid density $\rho_{\mathrm{s}}$. This relative density is an expression of the solid fraction.

It has not been possible to make material without voids, and for this reason to measure experimentally $\rho_{\mathrm{s}}$. Indeed, the mixing of the polymer matrix and of the polyisocyanate introduces air bubbles which are entrapped during the polymerisation reaction. The $\rho_{\mathrm{s}}$ value has been estimated by calculation, considering the density of the different components of the polyurethane, their proportion and a mixing law. A $\rho_{\mathrm{s}}=1180 \mathrm{~g}^{-1}$ value has been estimated, this is in the density range of polyurethane density reported in the literature [1]. The different relative densities obtained vary from 0.33 up to 0.85 . This is a density range more spread than in previous published works devoted to high density polyurethane foams $[1,10,14,15]$. For the latters, the relative density was limited to a maximum of 0.6.

\section{Technical}

\subsection{Differential scanning calorimetry}

The glass transition temperature of the samples has been characterised with a Pyris Diamond from Perkin-Elmer: to erase the thermal history of the samples, a first temperature ramp is applied with a speed of $10^{\circ} \mathrm{C} / \mathrm{min}$ in between $-10^{\circ} \mathrm{C}$ and $130^{\circ} \mathrm{C}$. After cooling $\left(-100^{\circ} \mathrm{C} / \mathrm{min}\right)$, a second ramp is performed within the same conditions. For the study of the ageing effect, after erasing the thermal history of the samples in the same manner; the samples are kept at ambient temperature during the desired ageing time; then a measurement (i.e. a heating ramp; $10{ }^{\circ} \mathrm{C} / \mathrm{min}$ ) is performed in the DSC.

\subsection{Electron microscopy}

The characterisation of the microstructure and the cell size of polyurethane foam is performed with a scanning electron microscope (SEM) JEOL 840 ALGS, with a filament tension of $10 \mathrm{kV}$. First, the samples are broken in liquid nitrogen. Then the fracture surfaces are gold coated to make them conducting. The micrographs obtained are treated by image analysis with the software Scion Image to quantify the size distribution of the voids in the foam. The apparent diameters of the pores are determined with the assumption of their sphericity. The Saltikov method [16], based on the discretisation of the radius distribution of the discs measured on the images, enabled the determination of the real diameters of the voids. 


\subsection{Mechanical tests}

The elastic $\left(G^{\prime}\right)$, and viscous $\left(G^{\prime \prime}\right)$ moduli, and $\tan \phi$ have been measured by dynamic mechanical analysis on an apparatus Mecanalyser (Metravib SA) developed in the laboratory [17]. It is an inverted torsion pendulum working in forced harmonic regime, at low frequency, from $10^{-5} \mathrm{~Hz}$ up to $5 \mathrm{~Hz}$, on a temperature range $T$ from $-170^{\circ} \mathrm{C}$ up to $400{ }^{\circ} \mathrm{C}$. The samples tested are parallelepipeds of $15 \mathrm{~mm}$ length, $5 \mathrm{~mm}$ width and $1.5 \mathrm{~mm}$ thickness. They are submitted to sinusoidal torsion, with controlled deformation (around $10^{-4}$, i.e. in the linear domain) at a frequency $f=0.1 \mathrm{~Hz}$. A temperature ramp is performed during the test from $-6^{\circ} \mathrm{C}$ up to $130{ }^{\circ} \mathrm{C}$ with a heating rate $\mathrm{d} T / \mathrm{d} t$ of $1{ }^{\circ} \mathrm{C} / \mathrm{min}$. Preliminary tests have shown that humidity does not affect the mechanical properties of the tested foams.

Uniaxial compression tests have been performed on a tensile test machine Instron 8510. The compression plateaus are maintained parallel by a guidance device with ball bearings. This machine possesses a thermo-regulated chamber to perform tests at temperatures in between $-90{ }^{\circ} \mathrm{C}$ and $230^{\circ} \mathrm{C}$. The tested samples are cylinders with $10 \mathrm{~mm}$ diameter for $20 \mathrm{~mm}$ high (a compromise to avoid buckling and barrel-like deformation) [18]. The samples are carefully prepared so that their contact surfaces be strictly parallel. To decrease friction, they are polished and a lubricant is used (molybdenum bisulphur). Tests have been performed at $30{ }^{\circ} \mathrm{C}$ with a constant crosshead speed corresponding to an initial strain rate of $10^{-3} \mathrm{~s}^{-1}$. The results are presented in nominal stress and strain.

\section{Results and discussion}

\subsection{Physical characterisation}

Preliminary tests by DSC have shown a physical ageing of those polyurethane foams (Fig. 1). It is evidenced by the

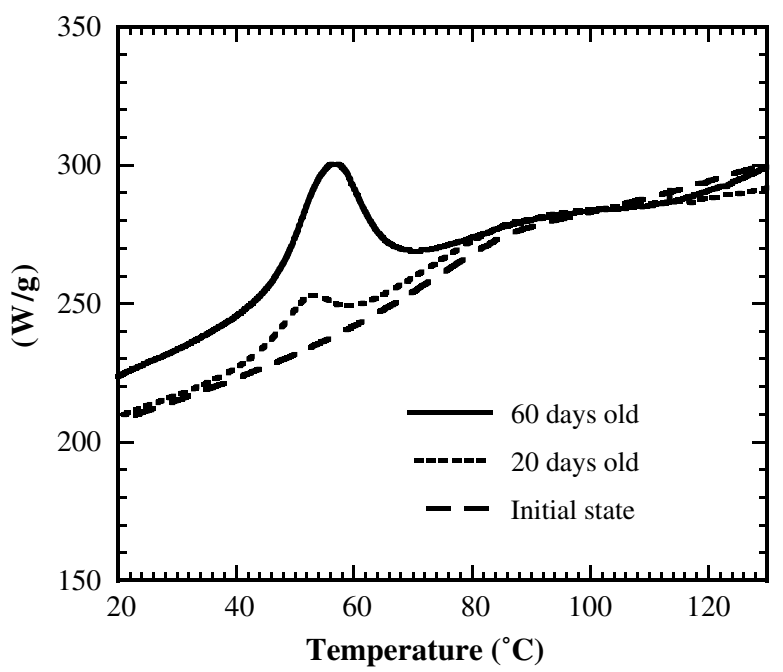

Fig. 1. Tests by differential scanning calorimetry for a foam with different aging stages. $\rho_{\mathrm{f}} / \rho_{\mathrm{s}}=0.42, T=-10$ up to $130^{\circ} \mathrm{C}, \mathrm{d} T / \mathrm{d} t=10^{\circ} \mathrm{C} / \mathrm{min}$. presence of an endothermic peak around $60{ }^{\circ} \mathrm{C}$. Physical ageing of polymer has already been reported in literature by Muzeau et al. [19]. It has consequences on the mechanical properties whatever the foam density, such as an increase of both the initial modulus and the stress peak value (Fig. 2). For this reason a thermal treatment has been performed to be sure that the thermal history of each sample is the same. Before each mechanical test, the samples are kept $10 \mathrm{~min}$ at $80^{\circ} \mathrm{C}$ (rejuvenation above $T_{\mathrm{g}}$ ) then $24 \mathrm{~h}$ at $25^{\circ} \mathrm{C}$. Indeed, it was checked that a supplementary ageing of the samples during the time needed to perform DMA or compression tests has no influence on the curves obtained from these tests.

Polyurethane foams have been analysed by DSC. Fig. 3 shows a large glass transition temperature. The glass transition temperature, measured at the onset of the transition is constant, whatever the foam density, and equal to $74 \pm 2{ }^{\circ} \mathrm{C}$.

By comparison, measurements performed by dynamic mechanical analysis (Fig. 3) have shown a temperature of the main relaxation taken at the maximum of $\tan \phi$ equal to $83{ }^{\circ} \mathrm{C}$, whatever the foam density. These results confirm those obtained by DSC: no significant modification of the polymer matrix is observed. However, for the lowest density foam, a supplementary relaxation is detected around $10{ }^{\circ} \mathrm{C}$. During the processing of the latter, the quantity of the water added is more important. The reaction of this water with isocyanate functions leads not only to the formation of carbon dioxide but also to the synthesis of urea, which can react with isocyanate or lead, by secondary reactions, to more or less crosslinked products. Thus, domains with important concentration of these sub-product of reactions [20] can be generated, in which molecular mobility is

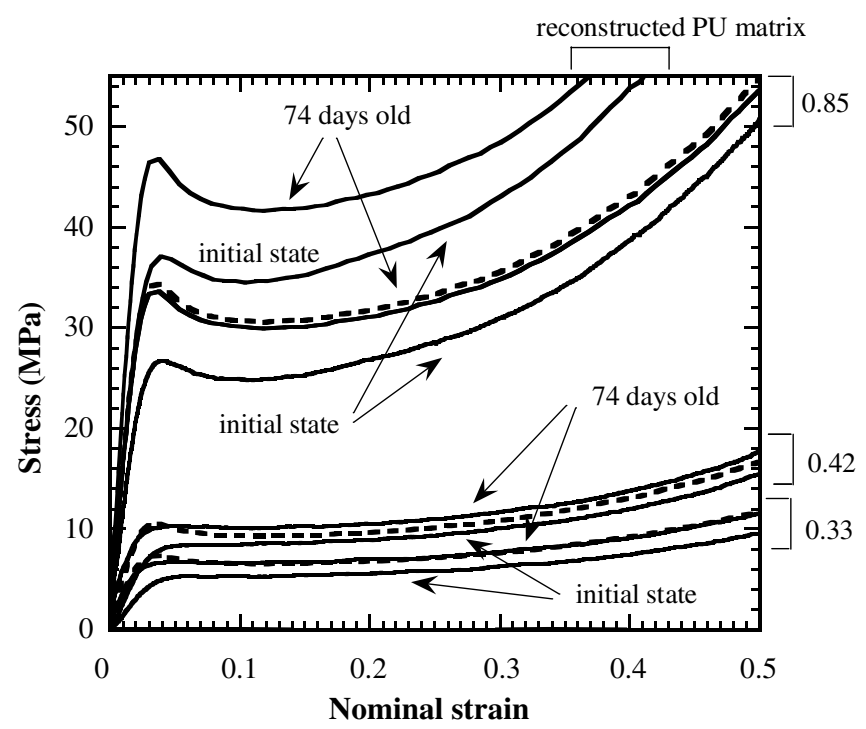

Fig. 2. Compression curves of polyurethane matrix and foams with different aging stages. The values on the curves represent the relative density. The polyurethane matrix curves are calculated from the dilute sphere and the high density foam $\left(\rho_{\mathrm{f}} / \rho_{\mathrm{s}}=0.85\right)$. The dash lines represents the simulated values. Initial strain rate $=10^{-3} \mathrm{~s}^{-1}, T=30^{\circ} \mathrm{C}$. 


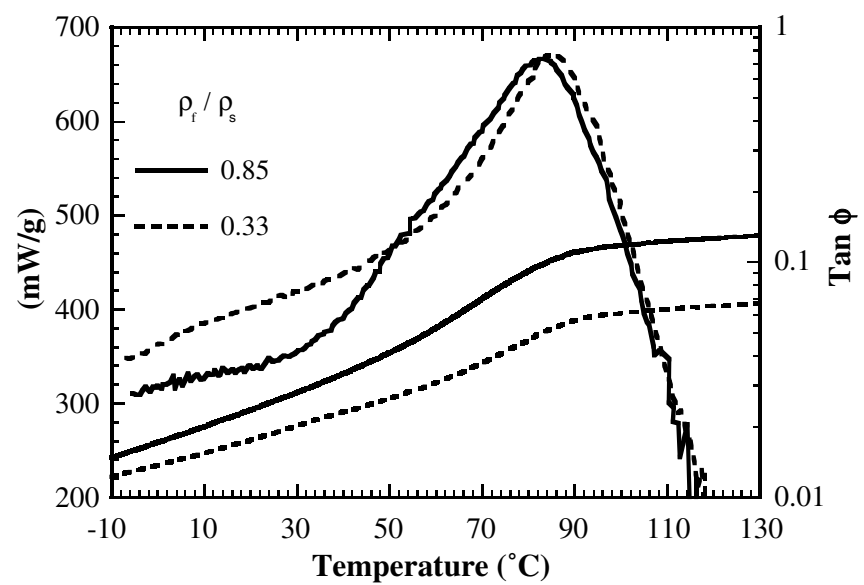

Fig. 3. Analyse by differential scanning calorimetry and DMA for the different foams processed. The values on the curves represent the relative density. $T=-10$ up to $130^{\circ} \mathrm{C}, \mathrm{d} T / \mathrm{d} t=10^{\circ} \mathrm{C} / \mathrm{min}$ for test by DSC. $f=0.1 \mathrm{~Hz}, T=-10$ à $130^{\circ} \mathrm{C}, \Delta T=1{ }^{\circ} \mathrm{C} / \mathrm{min}$ for test by DMA.

different from that of polyurethane chain. However, considering the low intensity of the secondary relaxation observed, one can conclude that whatever the relative density, the different foams present polymer matrix identical. This will be confirmed below.

\section{Morphological characterisation}

It is important to examine the foam structure in the density range studied, to know the most appropriate modelling of mechanical properties [21]. Foam observations by scanning electron microscopy show the formed cells (Fig. 4). In the density range studied (0.85-0.33), the cells essentially appear spherical and closed. The foam density is controlled by the gas quantity released during the water/isocyanate reaction. This affects the number of cells and their size. From the real diameter distribution of the cells (Fig. 5), deduced from image analysis, it is possible to adjust the parameters of a Gaussian distribution to estimate its width and the average real diameter (Fig. 6). For relative density above 0.85 , the cell average size is $15 \mu \mathrm{m}$, with a narrow distribution. Foams with density between 0.51 and 0.66 have all a distribution of cell size which widens when the

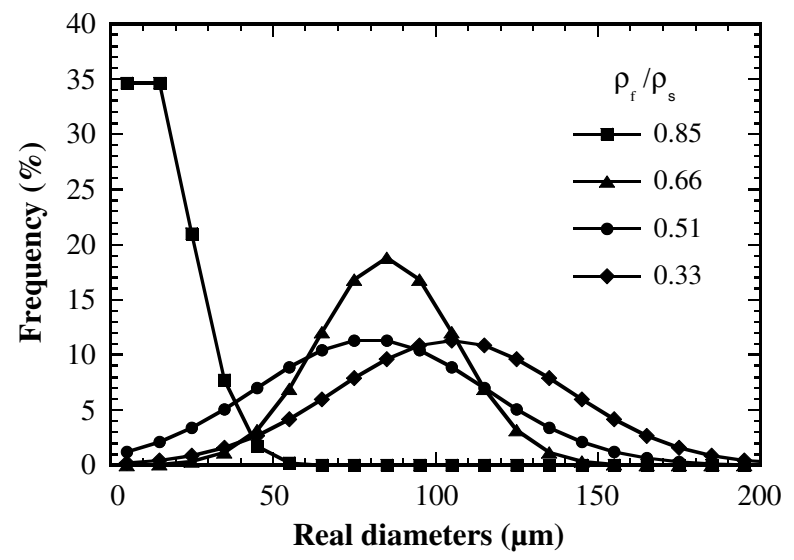

Fig. 5. Reconstructed real diameters distribution of the foams cells as a function of relative density.

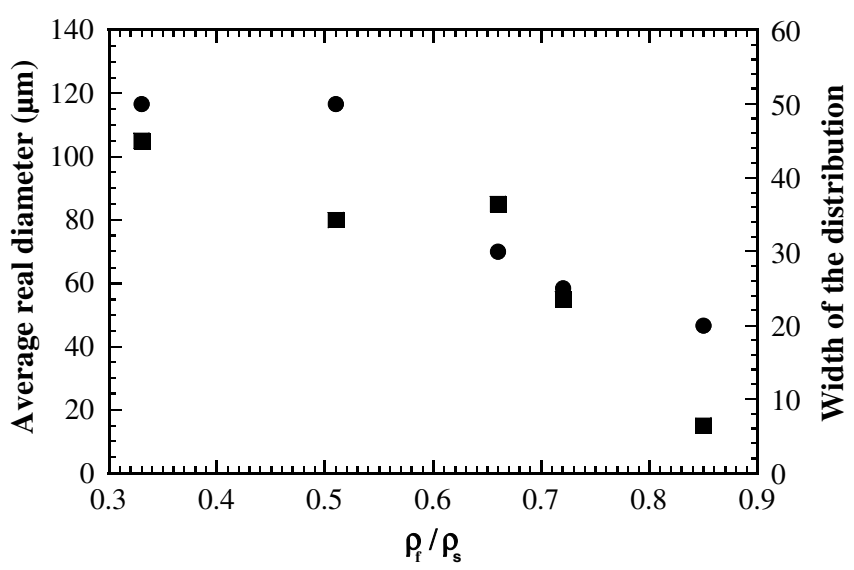

Fig. 6. Average real diameter (square) and distribution width (circle) of the cells of foams as a function of relative density.

density decreases and an average size well above that of the 0.85 density foam, of the order of $80 \mu \mathrm{m}$. One can observe for the lowest density foam (0.33) an average size of $105 \mu \mathrm{m}$ with a relatively similar distribution. The understanding of the nucleation, growth and stabilization processes of the bubbles involved in the generation of this distribution is extremely difficult and not in the scope of this article.
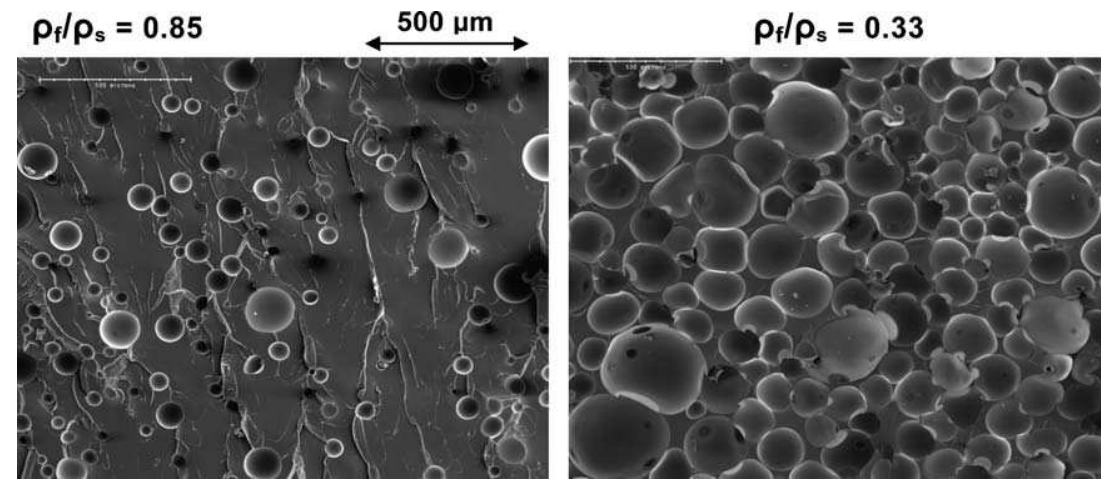

Fig. 4. SEM micrographs of foams. 


\subsection{Mechanical properties}

Dynamic mechanical analyses have been performed on foams with density 0.85 and 0.27 . Elastic $\left(G^{\prime}\right)$ and viscous $\left(G^{\prime \prime}\right)$ modulus as a function of temperature are presented on Fig. 7. The density decrease leads to a decrease of the levels of the glassy plateau and of the rubber plateau. The two curves are parallel (in logarithmic scale) and are only shifted by a factor. Fig. 8 presents the evolution of the $G^{\prime}$ moduli as a function of the relative density at $30{ }^{\circ} \mathrm{C}$. As expected, the modulus increases with the density.

Compression tests have been performed at $30^{\circ} \mathrm{C}$ (Fig. 9). For each curve, three domains can be distinguished. Using microscopy analysis, Gibson and Ashby [1] have associated each domain to a deformation mecha-

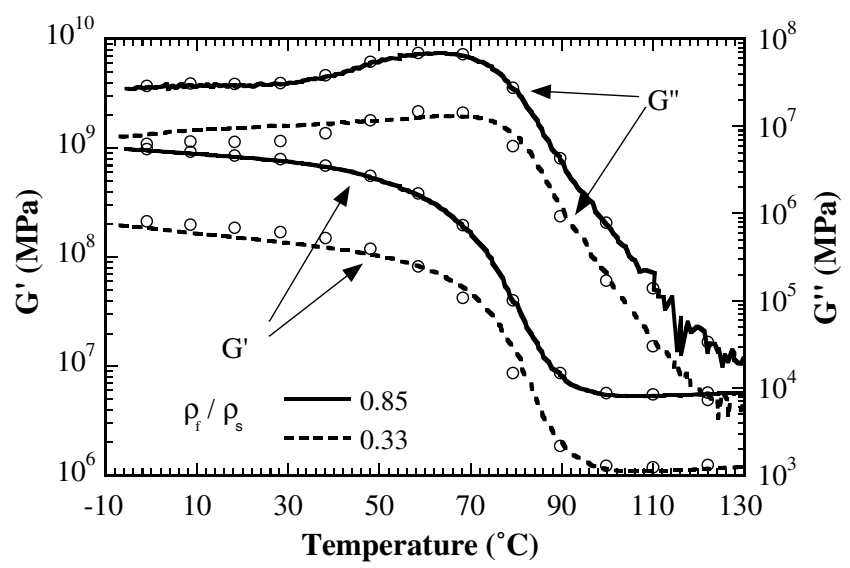

Fig. 7. Evolution of elastic modulus $\left(G^{\prime}\right)$ and loss modulus $\left(G^{\prime \prime}\right)$ as a function of temperature obtained by DMA. The values on the curves represents the relative density. The circles represents the predicted values with the $2+1$ phase modelling. $f=0.1 \mathrm{~Hz}, T=-10$ up to $130^{\circ} \mathrm{C}, \mathrm{d} T /$ $\mathrm{d} t=1{ }^{\circ} \mathrm{C} / \mathrm{min}$

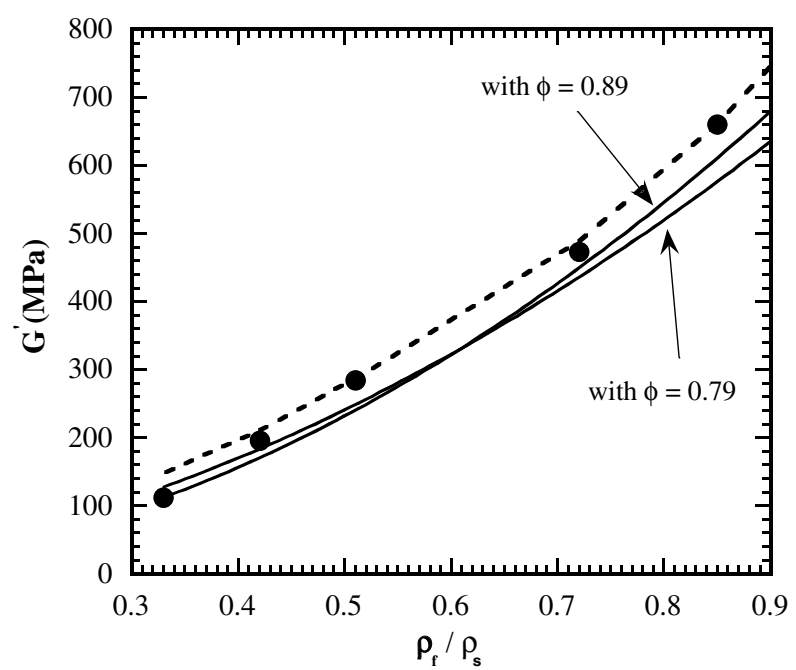

Fig. 8. Evolution of elastic modulus $\left(G^{\prime}\right)$ as a function of relative density obtained by DMA. The lines represent the predicted values with the Gibson and Ashby modelling [1]. The dash line represents the predicted values with the $2+1$ phase modelling. $f=0.1 \mathrm{~Hz}, T=30^{\circ} \mathrm{C}$.

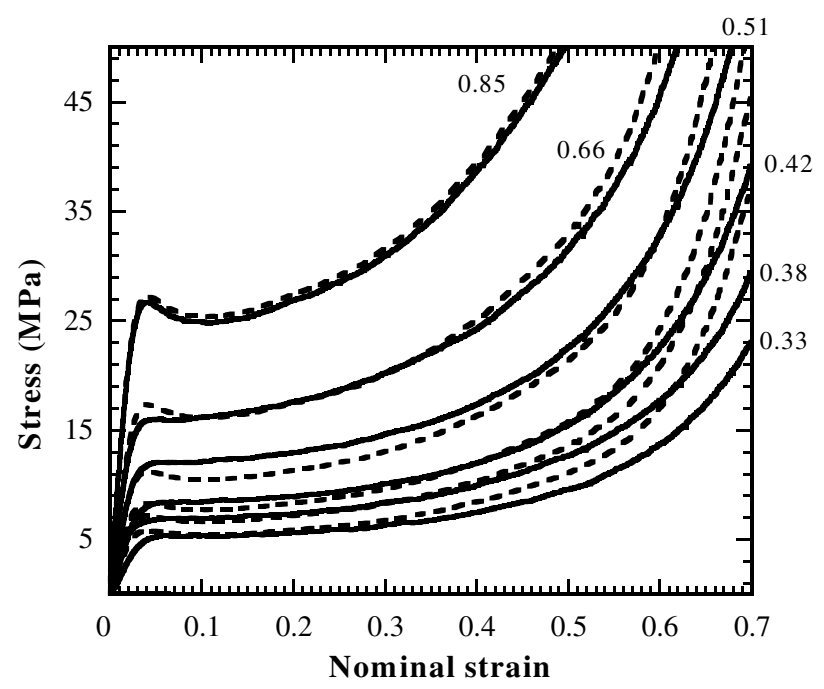

Fig. 9. Compression tests for different relative density foams. The values on the curves represents the relative density. The dash lines represents the predicted values with the phenomenological modelling. Initial strain rate $=10^{-3} \mathrm{~s}^{-1}, T=30^{\circ} \mathrm{C}$.

nism. The first domain is linear and corresponds to the viscoelastic response of the material. The initial slope of the stress-strain curve is the Young's modulus. In the second domain, the curve presents a large plateau. The stress value at the beginning of the plateau is noted $\sigma_{\mathrm{f}}$ and will be called hereafter the yield stress. Then, the material deformation involves either plastic deformation or rupture of the cell walls of the foam. The stress is constant until all the cells are crushed. The strong increase of the stress, identified as the third domain of the curve corresponds to the densification of the foam and finally to the polymer hardening. $\sigma_{\mathrm{f}}$ is plotted as a function of the density in Fig. 10. As expected, $\sigma_{\mathrm{f}}$ increases with the density.

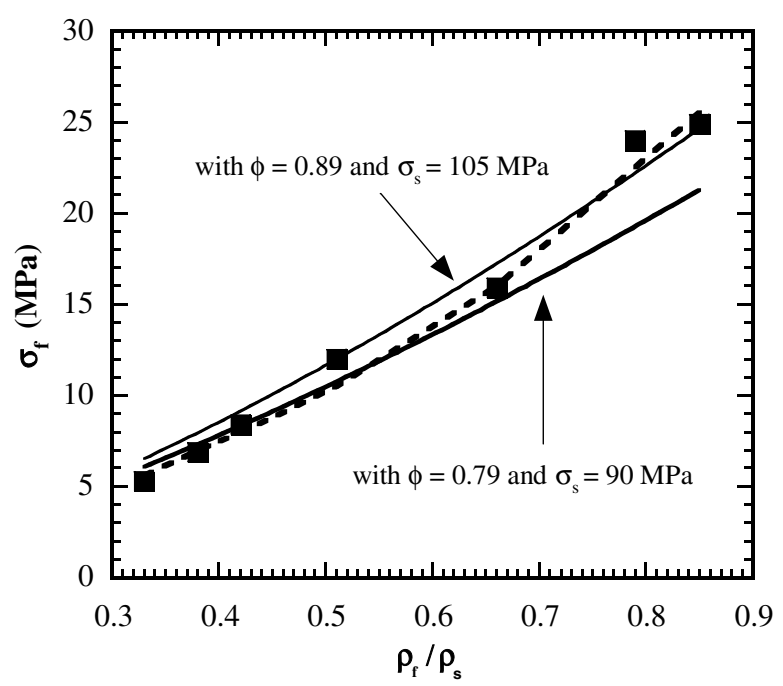

Fig. 10. Evolution of the stress value at the beginning of the plateau $\left(\sigma^{*}\right)$ as a function of relative density obtained by compression tests. The lines represents the predicted values with the Gibson and Ashby modelling [1]. The dash line represents the predicted values with the phenomenological modelling. Initial strain rate $=10^{-3} \mathrm{~s}^{-1}, T=30^{\circ} \mathrm{C}$. 
These experimental results have been compared to the Gibson and Ashby prediction [1] and to the $n+1$ phases modelling of Hervé and Zaoui [22] (with $n=2$, similar to the Christensen and Lo modelling [12]) in the linear domain.

\subsection{Modelling of the linear domain}

In the Gibson and Ashby modelling [1], closed cell foams are described like an arrangement of cubic cells constituted of struts and walls (Fig. 11a). For closed cells foam the polymer is distributed between the cell struts and the cell walls. The stiffness of the closed cells results from three components. The first comes from the strut flexion (like for open cell foam). The second component is due to the stretching of the cell walls. The third component is the contribution of the gas pressure inside the closed cell. Taking into account all theses components, Gibson and Asbhy [1] expressed the elastic modulus for closed cell foam as follows:

$\frac{E_{\mathrm{f}}}{E_{\mathrm{s}}} \approx \phi^{2}\left(\frac{\rho_{\mathrm{f}}}{\rho_{\mathrm{s}}}\right)^{2}+(1-\phi) \frac{\rho_{\mathrm{f}}}{\rho_{\mathrm{s}}}+\frac{\rho_{0}\left(1-2 v_{\mathrm{f}}\right)}{E_{\mathrm{s}}\left(1-\rho_{\mathrm{f}} / \rho_{\mathrm{s}}\right)}$

where $\phi$ is the polymer fraction in the struts. $\rho_{f} / \rho_{\mathrm{s}}$ is the relative density, $E_{\mathrm{s}}$ is the modulus of the constitutive material and $v_{\mathrm{f}}$ is the Poisson coefficient of the foam. The low initial pressure of the gas $\rho_{0}$ (in our case, the atmospheric pressure), makes the third term of the equation negligible. Moreover, making the assumption that the Poisson coefficient is constant whatever the foam density $\left(v_{\mathrm{f}}=1 / 3\right)$, Gibson and Ashy [1] also gave the expression of the shear modulus of the foam:

$\frac{G_{\mathrm{f}}}{G_{\mathrm{s}}} \approx \phi^{2}\left(\frac{\rho_{\mathrm{f}}}{\rho_{\mathrm{s}}}\right)^{2}+(1-\phi) \frac{\rho_{\mathrm{f}}}{\rho_{\mathrm{s}}}$

Another modelling approach has been explored, using the $2+1$ phase of Christensen and Lo [12], also called the generalised self consistent scheme, which allows the descrip- tion of the behaviour of composite material with matrix inclusion morphology. The polyurethane foam has been considered as a void inclusion/polymer composite. The $2+1$ phase modelling is defined by a representative volume element depicted in the Fig. 11b. The void inclusion is embedded in a connective phase (polymer matrix) which is itself placed in the unknown effective medium. For the general equation of this model, the readers are invited to consult the original articles. The specific case of void inclusions with a modulus and a Poisson coefficient equal to zero leads to the following equations:

$\frac{K_{\mathrm{f}}-K_{\mathrm{s}}}{-K_{\mathrm{s}}}=\frac{c}{1+\left[\frac{(c-1) K_{\mathrm{s}}}{K_{\mathrm{s}} \frac{4}{3} G_{\mathrm{s}}}\right]}$

where $K$ is the bulk modulus and the subscript s and $\mathrm{f}$ refer to the solid and foam, respectively. $c$ the inclusion volume fraction and $G$ is the effective shear modulus solution of the following equation:

$A\left(\frac{G_{\mathrm{f}}}{G_{\mathrm{s}}}\right)^{2}+B\left(\frac{G_{\mathrm{f}}}{G_{\mathrm{s}}}\right)+D=0$

where

$$
\begin{aligned}
A= & \left(1568-1480 v_{\mathrm{s}}^{2}-776 v_{\mathrm{s}}\right) c^{10 / 3}+\left(56 v_{\mathrm{s}}-740 v_{\mathrm{s}}^{2}-2156\right) c^{7 / 3} \\
& -7056 c^{5 / 3}+\left(11200 v_{\mathrm{s}}^{2}-16800 v_{\mathrm{s}}+9800\right) c \\
& +5600 v_{\mathrm{s}}^{2}-11760 v_{\mathrm{s}}+5488 \\
B= & \left(196-246 v_{\mathrm{s}}+60 v_{\mathrm{s}}^{2}\right) c^{10 / 3}+\left(1480 v_{\mathrm{s}}^{2}-112 v_{\mathrm{s}}+1078\right) c^{7 / 3} \\
& +14112 c^{5 / 3}+\left(4200 v_{\mathrm{s}}^{2}-12600 v_{\mathrm{s}}\right) c+6300 v_{\mathrm{s}}^{2} \\
& +11760 v_{\mathrm{s}}-4116 \\
D= & \left(740 v_{\mathrm{s}}^{2}-56 v_{\mathrm{s}}-1372\right) c^{10 / 3}+\left(56 v_{\mathrm{s}}-740 v_{\mathrm{s}}^{2}-2156\right) c^{7 / 3} \\
& -7056 c^{5 / 3}+\left(4900-700 v_{\mathrm{s}}^{2}\right) c+192080-137200 v_{\mathrm{s}}^{2}
\end{aligned}
$$

where $v_{\mathrm{s}}$ is the Poisson coefficient.

The application of the equivalence principle of Hashin [23], enables to extend these models to the viscoelastic

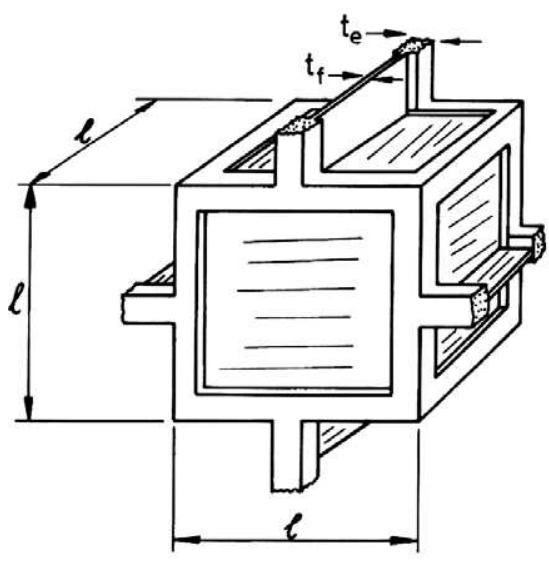

(a)

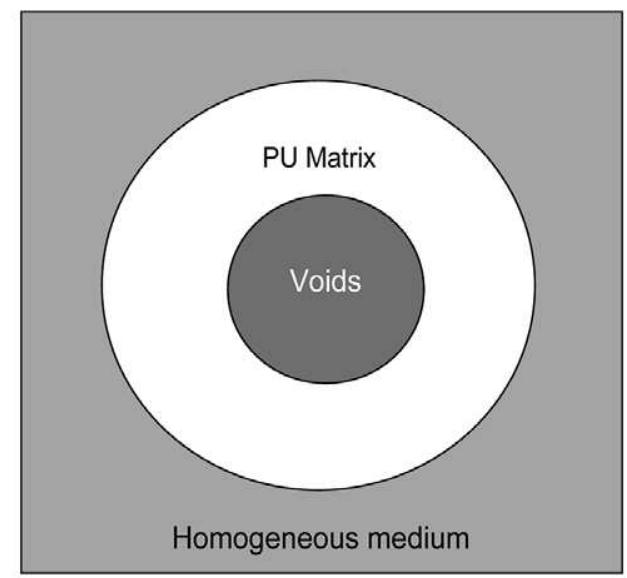

(b)

Fig. 11. (a) Cubic cell used for the Gibson and Ashby modelling [1] of closed cells foams. The cell is constituted of struts (length $l$, thickness $t_{\mathrm{e}}$ ) and walls (thickness $t_{\mathrm{f}}$ ). (b) schematic representative volume element used in the $2+1$ phase modelling. 
behaviour. It can be simply done by replacing the elastic terms of the previous equations by their complex counterpart. Note that largely above or below the main relaxation temperature, the loss modulus of the polymer, being much smaller than the elastic one, can be neglected; thus, the previous equations can be directly applied to predict the foam elastic modulus measured by mechanical spectrometry.

To model the behaviour of the studied foam, it was necessary to previously estimate the shear modulus of the polyurethane matrix. Indeed, as said above, it was impossible to elaborate polyurethane material without bubbles, and consequently to measure its mechanical properties. The 2+1 phase model [12] and the dilute sphere approaches [24] are equivalent at low fraction of inclusion (below 20\%vol). The second one gives the equation (isolated sphere in an homogeneous and infinite matrix):

$G_{\mathrm{c}}=G_{\mathrm{s}}\left(1-\frac{15\left(1-v_{\mathrm{s}}\right)\left(1-G_{\mathrm{i}} / G_{\mathrm{s}}\right) c}{7-5 v_{\mathrm{s}}+2\left(4-5 v_{\mathrm{s}}\right) G_{\mathrm{i}} / G_{\mathrm{s}}}\right)$

where $G_{\mathrm{c}}$ is the composite shear modulus, $G_{\mathrm{s}}$ the matrix modulus, $G_{\mathrm{i}}$ the inclusion modulus, $v_{\mathrm{s}}$ the Poisson coefficient of the matrix, and $c$ the inclusion volume fraction. In the case of our materials, the inclusion is a void and its modulus is $G_{\mathrm{i}}=0$. The volume fraction $c$ is given by $1-\left(\rho_{\mathrm{f}} / \rho_{\mathrm{s}}\right)$. Eq. $(8)$ becomes

$G_{\mathrm{f}}=G_{\mathrm{s}}\left(1-1.87\left(1-\rho_{\mathrm{f}} / \rho_{\mathrm{s}}\right)\right)$

or

$G s=\frac{G_{\mathrm{f}}}{\left(1-1.87\left(1-\rho_{\mathrm{f}} / \rho_{\mathrm{s}}\right)\right)}$

Considering the denser foam (0.85) as constituted of isolated bubbles (as confirmed by SEM, Fig. 4), the shear modulus of the polyurethane can be deduced. At $30^{\circ} \mathrm{C}$, an elastic shear modulus $G_{\mathrm{s}}^{\prime}=920 \mathrm{MPa}$ was found. This value is within the expected range for modulus of polymer resins in the glassy domain. It is then introduced in the Gibson and Ashby equation [1] and the $2+1$ phase modelling [13]. A comparison of the calculations and of the experimental modulus are presented in Fig. 8.

The modulus is correctly described by the Gibson and Ashby modelling [1] when $\phi=0.89$ (Fig. 8). This parameter is univocally determined. The common values for polyurethane in literature are between 0.6 and 0.9 [1,14,25]. However, this model is based on an unrealistic description of the microstructure of these foams. Moreover, the $\phi$ parameter depends on the density range studied. For example, it is found $\phi=0.79$ when this range is reduced to $(0.3-$ $0.4)$. The modulus value of the foams with higher density are then largely underestimated. Through this example, it appears, in the case of our materials that $\phi$ does not have any clear significance and can be considered as an adjustable parameter.

There is no such adjustable parameter in the $2+1$ phase modelling. Fig. 7 shows that it correctly describes the $G$ ' evolution as function of the density. This modelling has been extended to that of the complex modulus as a func- tion of temperature. Comparison between theory and experimental results are presented on Fig. 7. Again, the agreement is excellent, for the elastic modulus as for the viscous one, whatever the temperature.

\section{Non linear domain}

\subsection{Gibson and Ashby}

For the non linear domain prediction, Gibson and Ashby have linked the yield stress obtained in compression tests with the yield stress of the constitutive material. They find the equation:

$\frac{\sigma_{\mathrm{f}}}{\sigma_{\mathrm{s}}} \approx 0.3\left(\phi \frac{\rho_{\mathrm{f}}}{\rho_{\mathrm{s}}}\right)^{3 / 2}+0.4(1-\phi) \frac{\rho_{\mathrm{f}}}{\rho_{\mathrm{s}}}$

where $\sigma_{\mathrm{s}}$ is the yield stress of the solid.

The evolution of yield stress predicted by Gibson and Ashby [1] is presented in Fig. 10. Taking the value of $\phi$ equal to 0.89 previously found, $\sigma_{\mathrm{s}}$ is deduced equal to $105 \mathrm{MPa}$. Given the experimental results and literature $[1,14]$, this value is largely above the experimental value. Previously, we have also found that $\phi$ changes with the density range studied. It was found $\phi=0.79$, when adjusting the curve for foam density between 0.3 and 0.4 . Using this value, it is found $\sigma_{\mathrm{s}}=90 \mathrm{MPa}$ which is still very different from the expected value. Therefore, this model is not adapted for foam density above 0.3 .

\subsection{Phenomenological modelling}

Instead of modelling our foams with the Gibson and Ashby approach [1], one can use a phenomenological approach stating that the composite nominal stress and nominal matrix stress relationship at a given nominal deformation and at a given relative density is proportional. We have found that an efficient way to simulate the curves of the different foams is to use a proportionality coefficient. This coefficient is given by the $2+1$ phase modelling used in the linear domain. This can simply be written for a given deformation as:

$\frac{\sigma_{\mathrm{f}}}{\varepsilon_{\mathrm{f}}=\varepsilon_{\mathrm{s}}}=F\left(\frac{\sigma_{\mathrm{s}}}{\varepsilon_{\mathrm{s}}}, \frac{\rho_{\mathrm{f}}}{\rho_{\mathrm{s}}}\right)$

with $F$ the $2+1$ phase modelling applied to the matrix secant modulus at the strain level $\varepsilon_{\mathrm{s}}$ for a foam with a relative density $\rho_{\mathrm{f}} / \rho_{\mathrm{s}}$. Due to the absence of the compression curve of the matrix without bubbles, prior to the calculation of the curves with the different density foam, an inverse calculation as been done from the denser foam (with a density 0.85 ) to simulate a matrix compression curve. As shown in Fig. 9, the calculated curves are in very good agreement with the experimental ones. In particular, the apparent yield stress is well reproduced (Fig. 10), as well as the stress level up to strain of 0.6 .

With the same approach, it has been possible to simulate the compression curves of the foams aged during 74 
days (Fig. 3). To do this, the aged matrix has been recalculated from the curve of the denser foam (0.85) (Fig. 10). The results of the calculation show a good simulations of the ageing effect (Fig. 3). This suggests that the increase of mechanical properties of all the foams by ageing is due to the same phenomenon, i.e. an identical ageing of the matrix they contain. This ageing is "physical" and not chemical since we have found that it is reversible. If it was only due to the structural relaxation of amorphous polymer, only an increase of the stress peak of the matrix would have been found and not that of the flow stress, as on the calculated curve (Fig. 3). This suggests that this ageing is a reordering of the semi-crystalline phases formed by products of secondary chemical reactions such as the polyureas [20].

This approach is efficient to simulate different experimental curves. However, its main drawback is to be disconnected from the real stress and strain fields inside the foams. A more rigorous and realistic approach is developed below.

\subsection{Secant modelling}

To model the non-linear behaviour of foams, the classical procedure of transforming, at a given stress, a non-linear problem into a linear one has been used. The chosen linearisation method is the secant method which has been coupled to the $2+1$ phase self-consistent estimate of the linearised overall properties used in the linear domain. According to the secant procedure, the nonlinear behaviour of each phase is approximated, at a reference stress which is set equal to the average stress fields over the phase, by a linear behaviour defined by the instantaneous secant moduli. Given the inclusion volume fraction $\phi$, one writes:

$\left\langle\sigma_{\mathrm{c}}\right\rangle=\phi\left\langle\sigma_{\mathrm{i}}\right\rangle+(1-\phi)\left\langle\sigma_{\mathrm{m}}\right\rangle$

where the subscript $\mathrm{i}$ is for the inclusion and $\mathrm{m}$ is for the matrix.

Such a linearisation procedure leads to the definition of a linear comparison composite (LCC) exhibiting uniform fields per phase and whose effective properties can then be estimated using classical linear homogenisation schemes, i.e. the $2+1$ phase modelling. The procedure consists then, for each macroscopic stress, to repeat the two steps of linearisation and estimation of the effective properties of the LCC until, as prescribed by the secant method, the reference stresses are equal to the average stresses in the corresponding linearised phases. In the specific case of void inclusion, one can use the fact that the average stress in the inclusions are equal to zero. This leads to an average stress in the matrix which is already known:

$\left\langle\sigma_{\mathrm{m}}\right\rangle=\frac{1}{1-\phi}\left\langle\sigma_{\mathrm{c}}\right\rangle$

At the reference stress considered, the modulus of each phase are then univocally determined since the inclusion modulus is zero and the matrix modulus is the secant mod- ulus measured at the stress $\sigma_{\mathrm{m}}$. Then, the $2+1$ phase modelling gives the foam modulus from which is deduced its strain. The strain of the inclusion is deduced from the equation:

$\left\langle\varepsilon_{\mathrm{c}}\right\rangle=\phi\left\langle\varepsilon_{\mathrm{i}}\right\rangle+(1-\phi)\left\langle\varepsilon_{\mathrm{m}}\right\rangle$

The Poisson coefficient of the foam at each stress has also been calculated, taking a constant Poisson coefficient equal for the matrix to 0.33 and for the voids to 0 .

In order to compare this modelling with the experimental results, a preliminary problem has to be overcome, namely the determination of the properties of the pure matrix. They have been evaluated by inverse method, so that the prediction obtained for the foam with a density $d=0.85$ and the corresponding experimental behaviour are in agreement. Calculations obtained for the deduced matrix and the different foam densities are reported on Fig. 12. Note that the passage of theoretical curve calculated in true stress, and true strain and the experimental curves plotted in nominal stress and nominal strain is performed via the calculation of the Poisson coefficient which gives the volume and surface variation of the foam. Note also that this calculation has been performed with a constant Poisson coefficient of the matrix. We have checked that this approximation has no consequences on the discussion below.

Concerning the whole behaviour, one can observe that simulated yield peaks tend to be more pronounced than experimental ones, whereas, in the large deformation range, such modelling does not accurately account for the strong hardenings experimentally observed. This could be related to the simplicity of the modelling used (framework of nonlinear elasticity, no microstructure evolution), and to strong strain localisations which are not taken into account in the modelling. Further work is under program to deal

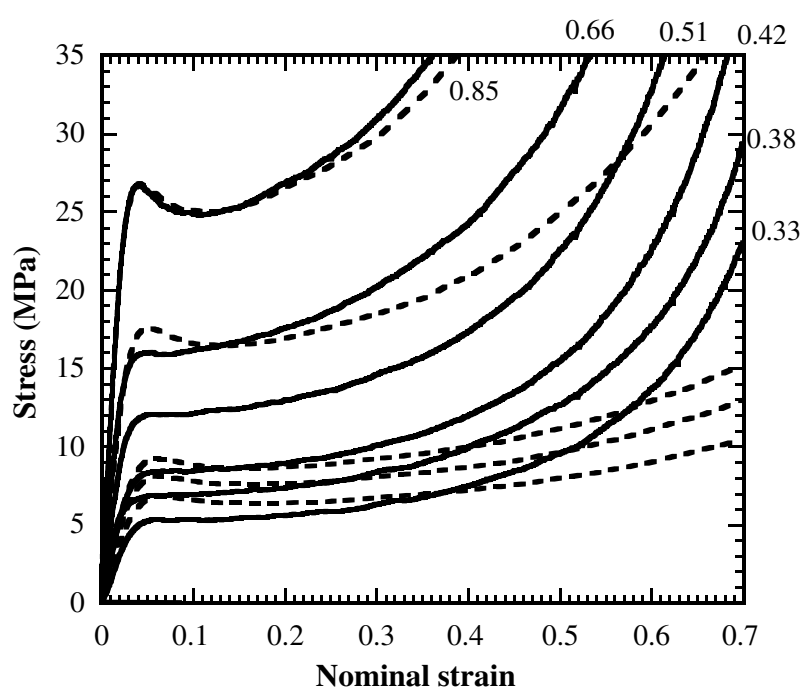

Fig. 12. Compression tests for different relative density foams. The values on the curves represents the relative density. The dash lines represents the predicted values with the secant modelling. Initial strain rate $=10^{-3} \mathrm{~s}^{-1}$, $T=30^{\circ} \mathrm{C}$. 
with hereditary behaviours, using the affine formulation [26] instead of the secant method.

\section{Conclusion}

Polyurethane foams with a relative density ranging between 0.3 and 0.85 have been processed. The microstructural characterisation evidenced their closed-cell morphology. The polymer matrix is found to be similar in all the foams as suggested by the very good modelling of their viscoelastic properties in the linear domain by the $2+1$ phase modelling. The Gibson Ashby modelling is less appropriate in the density range studied. The non linear behaviour has been correctly simulated by a phenomenological approach which arbitrarily uses a direct correspondence between the secant modulus of the matrix and that of the foam at a given strain, via the $2+1$ phase modelling used in the linear domain. This approach also enables a correct simulation of the ageing effect of the different foams. A more rigorous modelling approach, with a secant linearisation method of the stress-strain curves has not been able to model as well the experimental results because it did not take into account different effects such as the microstructural evolution, the anisotropic evolution of the material and its damage. Deformation localisation has also to be addressed to estimate its impact in the macroscopic behaviour. These points are currently studied in the laboratory, within the framework of a GDR "solid foam" [27] and will be the topic of future publications.

\section{Acknowledgements}

The authors acknowledge S. Youssef for its contribution to the experimental work and G. Vigier for fruitful discussion.

\section{References}

[1] Gibson LJ, Ashby MF. Cellular solids: structure and properties. Oxford: Pergamon Press; 1988.

[2] Schwartz D, Shi D, Evans A, Wadley H. MRS symposium San Francisco 1998; p. 521.

[3] Schulmeister V, Van Der Burg MWD, Van Der Giessen E, Marissen R. Mech Mater 1998;30:125.

[4] Youssef S, Maire E, Gaertner R. Acta Mater 2005;53(3):719.

[5] Gent AN, Thomas AG. J Appl Polym Sci 1959;2:354.

[6] Lerderman JM. J Appl Polym Sci 1971;15:693.

[7] Barma P, Rhodes MB, Salovery R. J Appl Phys 1978;49:4985.

[8] Christensen RM. J Mech Phys Solids 1986;34:563.

[9] Waren WE, Kraynik AM. ASME J Appl Mech 1988;55:341.

[10] Siegmann A, Kenig S, Alperstein D, Narkis M. Polym Compos 1983;4:113

[11] Kerner EH. Proc Phys Soc 1956;B69:808.

[12] (a) Christensen RM, Lo KH. J Mech Phys Solids 1979;27:315; (b) Erratum Christensen RM, Lo KH. J Mech Phys Solids 1986;34: 639

[13] Dieterich D, Uhlig K. Ullmann's Encyclopedia of Industrial Chemistry 1992;A21:665.

[14] Goods SH, Neuschwanger CL, Henderson CC, Skala ADM. J Appl Polym Sci 1998;68:1045.

[15] Miller Tate PC, Talal S. Polym Polym Compos 1999;7:117.

[16] Saltikov SA. Stereometric metallography. Moscou: Mettallurgizdat; 1958.

[17] Cavaillé JY, Salvia M, Merzeau P. Spectra 2000 1988;16:37.

[18] G'Sell C, Jonas JJ. J Mater Sci 1981;16:1956.

[19] Muzeau E, Vigier G, Vassoille R, Perez J. Polymer 1995;36:611.

[20] Kaushiva BD, McCartney SR, Rossmy GR, Wilkes GL. Polymer 2000;41:285.

[21] Dawson JR, Shortall JB. J Mat Sci 1982;17:220.

[22] Hervé E, Zaoui A. Int J Eng Sci 1973;31:1 (1993).

[23] Hashin Z. J Appl Polym Sci 1983;50:481.

[24] Einstein A. Ann Phy 1906;17:549.

[25] Reitz DW, Schuetz MA, Glicksman LR. J Cell Plast 1984;20: 104.

[26] Masson R, Bornert M, Suquet P, Zaoui A. J Mech Phys Solids 2000;48:1203.

[27] GDR, Research Group on Solid Foam, SPI_SC CNRS, contact Gérar.Vigier@insa-lyon.fr. 